\title{
CONCEPTUAL MODELING IN SIMULATION PROJECTS BY MEAN ADAPTED IDEF: AN APPLICATION IN A BRAZILIAN TECH COMPANY
}

\author{
José Arnaldo Barra Montevechi \\ Fabiano Leal \\ Alexandre Ferreira de Pinho \\ Rafael Florêncio da Silva Costa \\ Mona Liza Moura de Oliveira \\ Instituto de Engenharia de Produção e Gestão \\ Universidade Federal de Itajubá \\ Itajubá, MG, 37500-903, BRAZIL
}

André Luís Faustino da Silva

\author{
PadTec \\ Rodovia SP 340 - km: 118 \\ Campinas, SP, 3086-902, BRAZIL
}

\begin{abstract}
Several process modeling techniques have been used in simulation projects. However, most of these techniques provide little specific support to the programming. The main cause of this is the fact that these techniques were not developed with the same logic used in simulation models. From this issue, this paper presents an industrial application of a new conceptual modeling technique, named IDEF-SIM (Integrated Definition Methods - Simulation) currently under development by the authors. This adapted IDEF uses logic elements present in techniques such as IDEF0 and IDEF3, but in a way that is similar to the process interpretation logic usually used in simulation projects. This way, it can be noticed an increase in the conceptual model's utility, which might facilitate the simulation model programming, verification and validation and the scenarios creation. Additionally, the paper presents the benefits of using IDEF-SIM to create the conceptual model of a Brazilian tech company manufacturing cell.
\end{abstract}

\section{INTRODUCTION}

The computer simulation uses, in one of its phases, the conceptual modeling of processes. Perera and Liyanage (2000) state that conceptual modeling can increase the quality of simulation models, and yet reduce the time necessary for the construction of these computational models. This is the main reason why researchers (Perera and Liyanage 2000; Ryan and Heavey 2006; Greasley 2006; Chwif, Paul and Barreto 2006) present an interconnection between the processes mapping tools and simulation projects in their work.

Ryan and Heavey (2006) state that few modeling techniques used in BPM (Business Process Modeling) provide the necessary support for a simulation project. Still according to the referred authors, although there are many process mapping techniques, only a few focus on simulation projects. For this reason, some authors (Montevechi et al. 2008) have used a modeling techniques combination to try to surpass this lack of information.

The main characteristic of the IDEF-SIM technique is the identity of its application logic with the logic used in discrete-event simulation. This feature has the objective of creating a process's conceptual model, which contains required elements inside the computational modeling phase. This will make the future computational modeling easier.

According to Leal, Almeida, and Montevechi (2008), the use of the IDEF-SIM technique does not assure the registry of all required information by the computational model. However, IDEF-SIM has been 
developed with a focus on simulation. Therefore, it provides only the necessary information for the computational model.

The number of simulation software on the market has increasingly grown, allowing students who attend courses involving process simulation to opt for different software. Regardless of software used in teaching simulation in the academic realm, it is important to guide students in building well-structured conceptual models in order to facilitate the construction processes of the computational model, verification and validation. Thus, the IDEF-SIM will also contribute to the simulation teaching process.

Considering the importance granted to the conceptual modeling of processes and the lack of conceptual modeling techniques focusing simulation, this paper aims to highlight the application's benefits of using IDEF-SIM in the whole simulation project.

We begin positioning the conceptual model in a sequence of steps for a general simulation study in section 2. After that, the benefits of the applied technique, IDEF-SIM, are exposed in section 3 and the application of IDEF-SIM in a Brazilian tech company is shown in section 4. Finally, section 5 contains our concluding remarks.

\section{CONCEPTUAL MODEL IN DISCRETE EVENT SIMULATION PROJECTS}

Figure 1 shows an adapted flowchart from Montevechi et al. (2007), in which the proposed steps for a discrete-event simulation project are represented. In this diagram, three phases are shown and each one of them is characterized by a modeling stage: conception phase (conceptual model), implementation phase (computer model) and analysis phase (operational model).

Figure 1 clarifies the conceptual model importance, which is not only for the conception phase, but also to obtain the operational model (the verified and validated model that can be used to run scenarios), in the analysis phase. During the conceptual model creation, the main issue that might occur is the use of process mapping techniques, which were not developed focusing on simulation projects. This issue might prevent the conceptual model from entirely doing its objectives.

The conceptual model is a software independent description of the model that is to be constructed (Brooks and Robinson 2001). A conceptual model can guide the data collection stage, in a way to define the collection points, as well as to quicken the elaboration process of the computer model.

Out of all the activities involved in a simulation project, the conceptual modeling is probably the one that receives the smallest attention and, consequently, is the least understood. In a survey (Wang and Brooks 2007) it was verified that the conceptual modeling stage takes up a greater percentage of time in simulation projects when done by more experienced practitioners. This percentage drops significantly when the simulation project is performed by beginner practitioners in the area.

The nature of the conceptual model is very different from the steps of verification, validation and analysis of the results, which possess strong mathematical and statistical elements. Although from a different nature, the importance of the conceptual model in simulation projects is very significant.

Many conceptual modeling methods have been proposed. However, for Hernandez-Matias et al. (2008) there is no conceptual modeling method that is capable of entirely modeling a complex manufacturing process. Section 3 presents conceptual modeling through IDEF-SIM, seeking to minimize the problems which have been discussed. 


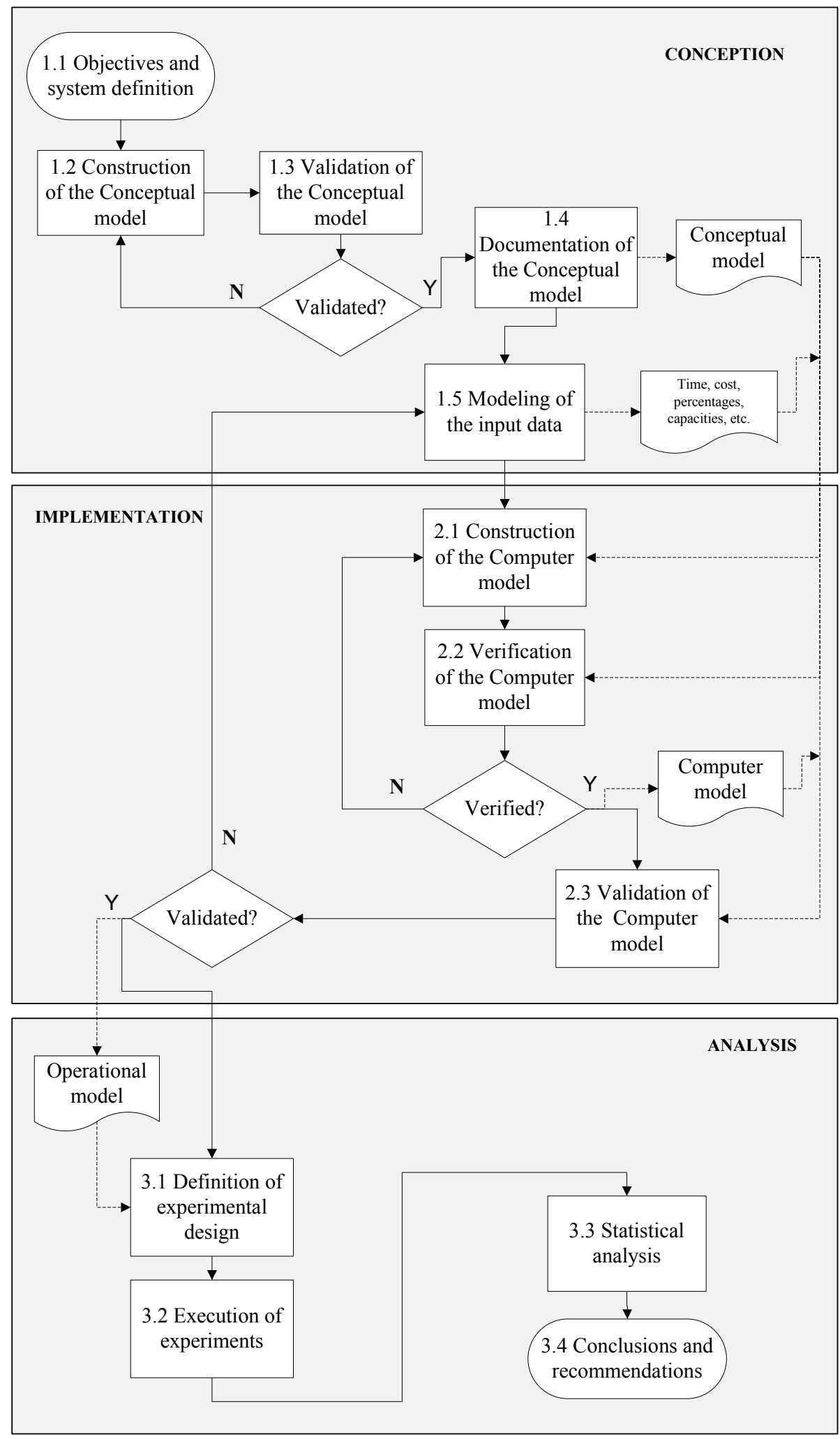

Figure 1: Sequence of steps for a simulation project. Source: adapted from Montevechi et al. (2007) 


\section{THE APPLIED TECHNIQUE: IDEF-SIM}

Although the IDEF0 and IDEF3 techniques (NIST 1993) present many applications on process modeling, they were not developed focusing on simulation. Therefore, the development and application of the IDEFSIM technique is presented next.

The main characteristic of IDEF-SIM is the similarity of its application logic with the logic used in discrete event simulation. This characteristic has as an objective the creation of a conceptual model of the process to be simulated that contains elements required in the computer modeling phase.

Conceptual modeling is probably the stage of discrete-event simulation that receives the least attention, and is consequently, the least understood. A probable cause of such diminished interest in conceptual modeling is the use of a technique that does not offer enough advantages for computer modeling, thus diminishing motivation to take special care with the conceptual model.

Figure 2 demonstrates this issue with conceptual models. Using conventional process mapping techniques, a conceptual model that is incapable of attending the computer model needs is obtained. Therefore there are three information sets:

- $\quad$ set A: information generated through conceptual modeling;

- set B: necessary information for computer modeling;

- $\quad$ set $\mathrm{C}$ : necessary information for computer modeling and available through conceptual modeling.

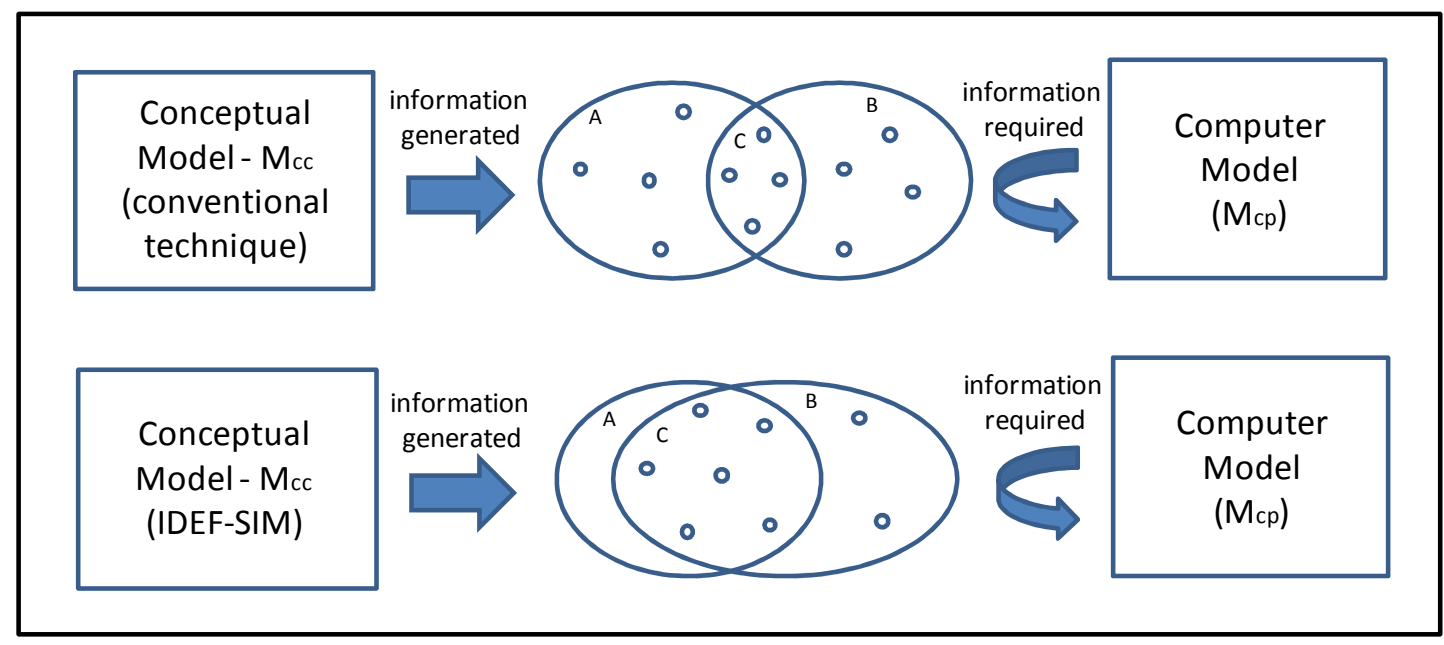

Figure 2: Sets A, B and C of generated and required information

Drawing an analogy with the pulled system widely discussed in works which approach lean manufacturing, it can be observed in Figure 2 that the computer model "pulls" the necessary information from the process, represented in set B. However, the conceptual model "pushes" information from the process to the computer model (set A). From the information pushed by the conceptual model, only the ones represented in set $\mathrm{C}$ are used in the computer model.

Set $\mathrm{C}$ for conventional conceptual modeling techniques contains a smaller amount of information, compared to the scenario where the conceptual model is done by the IDEF-SIM technique. Once again making an analogy with lean manufacturing, IDEF-SIM seeks to "push" the information that the computer model wishes to "pull". This is possible as the technique was developed from the point of view of the conceptual model.

Moreover, in the case of conventional modeling, a great amount of information required by the computer model is not contemplated by the conceptual model, which obliges the person responsible for the simulation to search for this information in the system to be simulated, consuming more time in this stage. 


\section{Montevechi, Leal, Pinho, Costa, Oliveira and Silva}

In general, the number of simulation specialists in companies is small, and in every new simulation project these specialists should actually go to the process to be simulated to perform the conceptual modeling. This occurs because, normally, the mapping which the company has contains insufficient information to be used by the simulation specialist in the project. The cause of this impossibility of use is that these mappings were not done focusing on the simulation. Thus, the presence of the simulation specialist in the process to be simulated becomes necessary, so that this specialist is able to perform the conceptual modeling with the information judged necessary.

To reduce theses costs, the employees themselves who are already allocated in the process to be simulated could perform the conceptual modeling and send the data to the simulation specialist, therefore speeding up the steps of a simulation. However, for the collected data by the employees to be well used by the simulation specialist, the logic used in the conceptual modeling must be similar to the one used later on by the specialist. In this sense, IDEF-SIM causes the conceptual model to be constructed in a way to maintain the logic to be used in the computer modeling phase.

It is important to emphasize that the use of the IDEF-SIM technique does not guarantee the register of all the required information in the computer model, as can be observed in Figure 2. However, IDEF-SIM, because it may have been elaborated focusing on simulation, provides only the necessary information for the computer model, leaving in set $\mathrm{C}$ all the elements belonging to set $\mathrm{A}$. As there are several simulation packages in the market, it is acceptable that remaining additional information, specific to the simulation package chosen, is not contemplated by IDEF-SIM. This is justified by the fact that the technique was not developed to contemplate a specific commercial simulation package, but to contemplate a common simulation logic found in the simulation packages.

In Figure 2 the clocked times are not considered in the information set required by the computer model. These times will be measured from the activities defined by the conceptual model. Gathering a lot of information in the conceptual model can make it difficult to interpret, thus deviating its main purpose, which is to facilitate the computer modeling work.

The logic elements used in the IDEF-SIM technique induces the person responsible for the conceptual model to focus on the information that later on is essential to the person responsible for the computer model.

The elements used to compose the IDEF-SIM technique were selected from the already acclaimed modeling techniques IDEF0, IDEF3, and flowchart. Although the IDEF techniques are apt for the modeling of systems, when used in simulation projects, they no longer register important aspects, for they were not structured for simulation projects. Hence, IDEF-SIM uses symbols from IDEF0, IDEF3 and flowchart, but within a logic that contemplates the simulation. Table 1 presents the used elements and symbol system.

Next, the role of each element presented in Table 1 is detailed:

1. Entity: represent the items to be processed by the system, representing raw material, products, people, documents, among others. They can be grouped or divided during the production process and are moved alone or through resources. Once represented, the symbol will only appear at the moment when a new entity is created. This way, the number of entities to be used and in which points of the model the entity will undergo a transformation becomes clear;

2. Functions: represent the places where the entity will undergo an action. Functions are understood as: work posts, conveyor belts, rows and stocks, and service posts. These functions can change an entity, such as in the service posts, or even alter the time of this entity on the flow, as a delay (rows, stock);

3. Entity flow: represent the direction of the entity in the model, characterizing the moment of input and output of the entities in the functions;

4. Resources: represent elements used for moving the entities and executing functions. The resources can represent people or equipment. In a system, there can be static or dynamic resources. 
The static resources are not endowed by movement. The dynamic resources, on the other hand, can move through an established path;

5. Controls: represent the rules used in the functions, such as sequencing, row rules, programming, among others;

6. Rules for parallel and/or alternatives flows: these rules are called junctions, in the IDEF3 technique. Two or more paths, after a function, can be executed together (junction AND), or in an alternative way (junction OR), or allowing both rules (junction AND/OR);

7. Motion: represents an entity displacement, in which the modeler believes to possess an important effect on the model. When this element is represented, a specific programming for this motion, with time spent and resource used is expected to be found, in the computer model;

8. Explanatory information: used to insert an explanation in the model, aiming at facilitating the understanding of the model;

9. Input flow in the modeled system: defines the input or the creation of entities in the model.

10. End of system: defines the end of a path inside the modeled flow. Everything that, in practice, is found beyond this point is out of the limits of the model;

11. Connection to other figure: used to divide the model into different figures.

Table 1: Elements and symbol system used in the IDEF-SIM technique.

\begin{tabular}{|c|c|c|}
\hline Elements & Symbology & Technique of origin \\
\hline Entity & & $\begin{array}{l}\text { IDEF3 (Transitions } \\
\text { description mode) }\end{array}$ \\
\hline Functions & & IDEF0 \\
\hline Entity Flow & & IDEF0 and IDEF3 \\
\hline Resources & & IDEF0 \\
\hline Controls & & IDEF0 \\
\hline \multirow{3}{*}{$\begin{array}{l}\text { Rules for parallel and/or } \\
\text { alternatives flows }\end{array}$} & Rule AND & \multirow[t]{3}{*}{ IDEF3 } \\
\hline & Rule OR & \\
\hline & Rule AND/OR & \\
\hline Motion & & Flowchart \\
\hline Explanatory information & $------>$ & IDEF0 and IDEF3 \\
\hline $\begin{array}{l}\text { Input flow in modeled } \\
\text { system }\end{array}$ & 4 & \\
\hline \multicolumn{3}{|l|}{ End of system } \\
\hline Connection to other figure & & \\
\hline
\end{tabular}




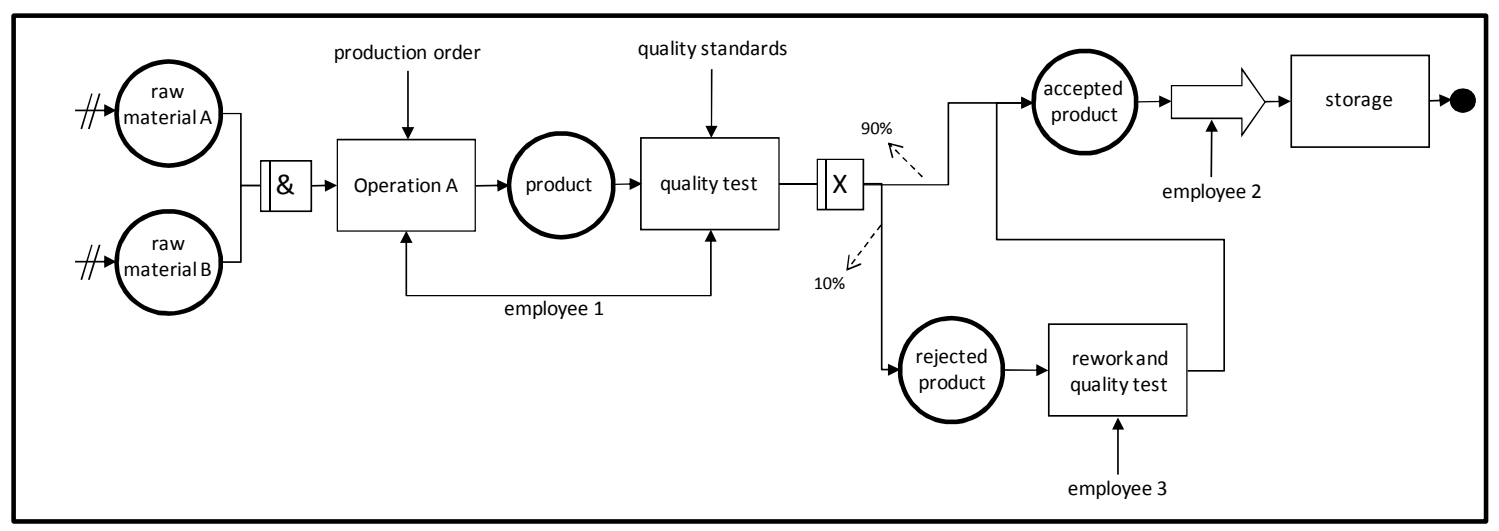

Figure 3: Example of application of the IDEF-SIM

In figure 3, which shows an example of IDEF-SIM using the presented symbol system, the function "Operation A" needs the entities "raw material A" and "raw material B". Only with these two entities will the function be able to execute its work, which is defined through a "production order" control and executed by a resource "employee 1". After operation A, the entity "product" is generated, which is taken to the function "quality test". This function is executed by the same resource "employee 1", which represents a restriction of the system. At this moment the conceptual model informs the computer model that the "quality test" function cannot occur while "operation A" occurs, due to the restriction of the resource.

After the quality test, the product will have two path options: it will either be considered an "accepted product", in $90 \%$ of the cases; or it will be considered a "rejected product", in $10 \%$ of the cases. The entity "accepted product" is transported by "employee 2" to the storage area, reaching the analysis limit of the model. In turn, the entity "rejected product" is processed in the function "rework and quality test", and converted in "accepted product", remaining like this until the end of the modeled system.

On this model in IDEF-SIM, important information in the computer modeling phase was already defined, such as the input points in the model, the entities and its transformation places, the functions to be modeled, the resources and its restrictions, the possible paths for the flow, the motion and the last point of the model.

Some important characteristics on the use of logic elements of IDEF-SIM distinguish it from other IDEF techniques, such as:

1. the characterization of the entities that enter the model, originated from processes out of the limits of the simulated model;

2. the use of a specific symbol for motion. Moreover, IDEF-SIM allows the registration of which resource is responsible for the motion;

3. the registration of the moments in which the entity is transformed, after the functions;

4. the use of the junctions not only before and after the functions (as done in IDEF3), but also on the resources and controls, as will be seen on the next item of this paper.

\section{APPLICATION OF THE PROPOSED TECHNIQUE}

To accomplish the objective of this study, one of Padtec's manufacturing cells was chosen. This cell assembles optical transponders. Since 2001, Padtec has been a Brazilian tech company that assembles pieces of equipment which form Wavelength Division Multiplexing optical systems.

Optical transponders represent almost $40 \%$ of the company's revenue, while optical amplifiers are the second major revenue product, corresponding to $20 \%$ of the company's revenue. 
By following the flowchart shown in Figure 1, the conception phase begins with the creation of the IDEF-SIM diagram. This constitutes the conceptual simulation model. It was built to improve the understanding of the cell production process, and to make the computational model construction easier.

According to Figure 4 and Table 2, the entities PCB (E1) and Raw materials (E2) arrive in the system and are sent to the organization activity. This activity will be executed by the operator using the resource workbench (R1), only with the two entities present.

Table 2: IDEF-SIM subtitle

\begin{tabular}{|l|l|}
\hline Symbol & Description \\
\hline Activities & \\
\hline Or & Organization of raw materials \\
\hline TA & Transponder assembly \\
\hline TC & Transponder configure \\
\hline TR & Transponder regulate \\
\hline R & Repair \\
\hline D & Discard \\
\hline T & Terminate \\
\hline Entities & \\
\hline E1 & Printed Circuit Board (PCB) \\
\hline E2 & Raw materials \\
\hline E3 & Assembled Transponder \\
\hline E4 & Case \\
\hline E5 & Transponder \\
\hline Resources & \\
\hline R1 & Workbench \\
\hline R2 & Workbench, equipment \\
\hline R3 & Workbench, computer, equipment \\
\hline R4 & Workbench, computer \\
\hline
\end{tabular}

After that, these entities (E1 and E2) are joined by the operator using the resources (R2) in the Transponder assembly activity (TA) by generating an assembled Transponder (E3). This E3 goes to the configuration activity (TC) and regulate (TR), both performed by the operator using resources (R3). In this process point, a transponder assembled (E3) might be joined with a case (E4) and be terminated (T) or might be repaired (R). If repaired, an assembled transponder (E3) might be discarded (D), and if so, leaves the system; or it might be returned to the terminating activity (T). Finally, after the terminating activity (T), a Transponder (E5) is carried by the operator to the system's exit.

Through this application at Padtec, it can be noticed that the conceptual model, built through IDEFSIM, made the computer model programming easier. The left of the figure 5 shows the computer model, built using Promodel, generated through IDEF-SIM, presented in figure 4.

In addition, the figure 4's section 1 shows the resource use cell operator to perform the transponder assembly and configure activities. The Promodel's programming block referred to section 1 is shown at the up right of the figure 5. In the same way, the figure 4's section 2 shows the entities flow probability. The Promodel's programming block referred to section 2 is shown at the bottom right of the figure 5. Therefore, this technique has the similarity of its application logic with the logic used to program in discrete event simulators. 


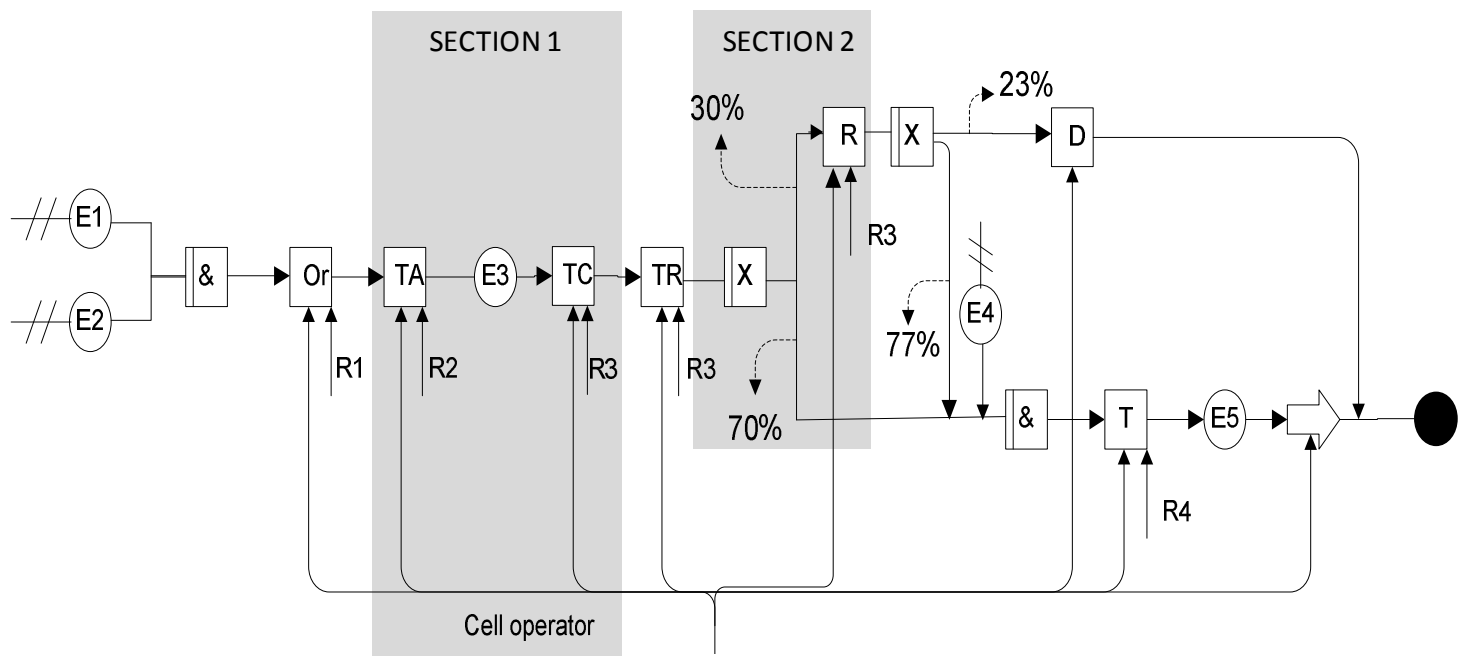

Figure 4: IDEF-SIM for the transponder assembly cell, the simulation conceptual model
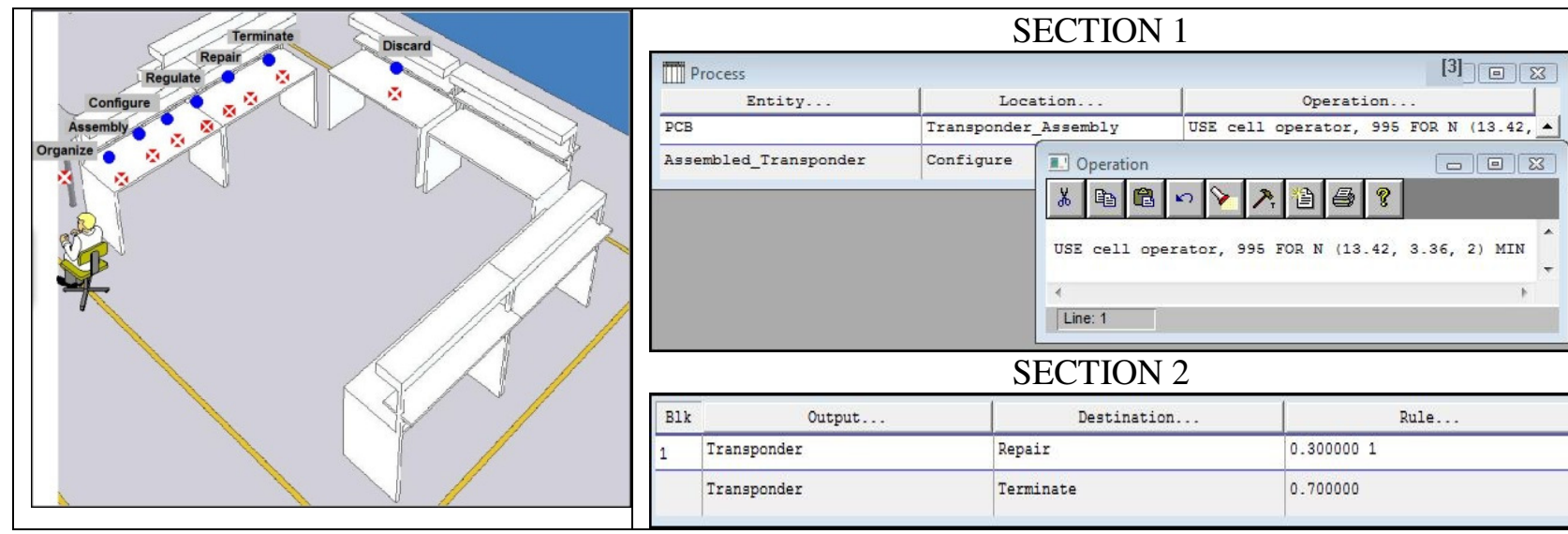

Figure 5: Screenshot of Promodel's programming block

Some benefits of using this technique can be pointed out as the identification of the resources that are required to perform each function, the indication of each entity's transformation after determined activity along with the entire process, the identification of the main system's arrivals and IDEF-SIM provides a great level of process' details.

Besides that, additional important information covered by this technique to facilitate the computer model construction is that the diagram provided the identification that the resource "cell operator" is required in all functions, even to carry products along with the process. This fact implies in a computer model restriction, a mean, an activity only can be executed if this resource is available.

We highlight here two main contributions that the IDEF-SIM technique might generate when costs are associated with simulation models (Costa et al. 2010). First, each process activity can be identified. This is an important step in $\mathrm{ABC}$ development. According to the $\mathrm{ABC}$ method, after this identification of all process activities, the next step is to allocate costs to activities. The second one is the advantage of identifying all the resources that are used during each activity. Based on this sort of information, the modeler might trace the electric energy costs, indirect labour and depreciation costs to only the activities which have the arrow entering on the lower border.

When IDEF-SIM was presented to Padtec's decision makers, it was noted that their data base was not able to answer the following questions: 
1. How many transponders need to be repaired after being regulated (TR)?

2. If a transponder goes to the repair activity, how many transponders are successfully repaired and returned to the normal flow to be terminated?

To answer these questions it was necessary to create two important indicators of the process efficiency. The first indicator measures the quantity of transponders which need to be repaired after the regulate activity (as mentioned in Figure 4, this current indicator corresponds to an average of $30 \%$, at the present level of training, and can be improved) and the second one considers the quantity of transponders which returns to the normal process flow (77\%). This was another important contribution of the IDEF-SIM diagram.

After that, the IDEF-SIM model was validated as being a good representation of Padtec's manufacturing cell by the process specialists. Then, the simulation project followed the flowchart, shown in Figure 1; however the further steps of this simulation project is not of interest in this paper.

\section{CONCLUSIONS}

This project presented adapted IDEF developed by the authors, with the purpose of creating a conceptual modeling logic similar to the logic used in the computer modeling in simulation projects. This way, the modeler, already in the conceptual model phase, can build a model, on site, that will facilitate the later work of the computer model.

The elaboration of the IDEF-SIM technique does not restrict its use to a determined simulation package. In this study Promodel ${ }^{\circledR}$ was used only to illustrate the conversion of a conceptual model into a computer model. The elements "function", "entity", "motion", "resources", "controls" are used in several different types of simulation software, but with specific names. Other elements are more characteristic of determined software, and for that reason they were not used on IDEF-SIM.

An important advantage observed in the use of the IDEF-SIM technique was the possibility to improve the face-to-face validation process with the process specialists, as the logic of IDEF-SIM is similar to the one used in the computational modeling process. Although in most cases the process specialists are not simulation experts, the face-to-face validation becomes more precise with the use of IDEF-SIM, as it registers what will be modeled in the simulation.

During the application of IDEF-SIM it was concluded that the technique can be used in two different moments of the simulation project. The first possibility is the use in the conceptual modeling phase, where the modeler registers the system to be simulated. The great benefit of using IDEF-SIM in this phase is the construction of a conceptual model with some characteristics that will allow time reduction in the computer modeling phase.

This conceptual model allowed Padtec's process specialists to identify an activity (transponder repairing) that should not exist inside the production process. This possibility was tested in a simulated scenario.

This scenario suggested that the operator should not repair transponders during the production process. Otherwise, by repairing transponders as the current process recommends, the final product cost and the activity costs are higher.

Another possibility is to use IDEF-SIM in the model's documenting phase. Once the computer model is concrete, the technique can be used to register the logic of the model, not only facilitating the task of verification and validation, but also allowing a greater understanding by the readers of the works.

Regardless of the simulation project, the model elaborated through this technique can also be used in improvement projects, through rationalization studies, location on occurrences of failure modes and its effects, besides the analysis of human participation in the process. The structure built from the combination of elements of IDEF0 and IDEF3 allows grouping the strengths of these two techniques. The understanding becomes easier, as these techniques are already used in research in the BPM (Business Process Modeling) area. 


\section{Montevechi, Leal, Pinho, Costa, Oliveira and Silva}

Finally, the IDEF-SIM is being used by the authors in the orientation of academic works that use simulation projects, both in graduate and post-graduate courses. These studies have shown that students have devoted more time in the preparation of conceptual models, anticipating the resolution of many problems which before were identified only in the computational modeling stage. New studies are being conducted to measure this gain attributed to the use of IDEF-SIM technique and its applicability to other simulation software.

\section{ACKNOWLEDGMENTS}

The authors would like to express their gratitude to CNPq, CAPES pro-engineering program, FAPEMIG and Padtec S.A. for their support throughout this research.

\section{REFERENCES}

Brooks, R.J., and S. Robinson. 2001. Simulation with inventory control. Operational research series, Basingstoke, Palgrave.

Chwif, L., R.J. Paul, and M.R.P. Barretto. 2006. Discrete event simulation model reduction: A causal approach. Simulation Modelling Practice and Theory 14 (7) 930-944.

Costa, R.F.S. da, J.A.B. Montevechi, M.S.F. Pamplona, A.L. Medeiros, A.L.F. da Silva, and J.D. Friend. 2010. Discrete-event simulation and activity-based costing to aid the decision making process in a manufacturing cell. Workshop on Applied Modeling and Simulation. May 5-7.

Greasley, A. 2006. Using process mapping and business process simulation to support a process-based approach to change in a public sector organization. Technovation 26 (1) 95-103.

Hernandez-Matias, J.C., A. Vizan, J. Perez-Garcia, and J. Rios. 2008. An integrated modeling framework to support manufacturing system diagnosis for continuous improvement. Robotics and computerintegrated manufacturing 24 (2) 187-199.

Leal, F., D.A. de Almeida, and J.A.B. Montevechi. 2008. Uma Proposta de Técnica de Modelagem Conceitual para a Simulação através de Elementos do IDEF. Anais do XL Simpósio Brasileiro de Pesquisa Operacional. João Pessoa (Paraíba, Brasil).

Montevechi, J.A.B, A.F. de Pinho, F. Leal, and F.A.S. Marins. 2007. Application of design of experiments on the simulation of a process in an automotive industry, , In Proceedings of the 2007 Winter Simulation Conference, eds. S. G. Henderson, B. Biller, M.-H Hsieh, J. Shortle, J. D. Tew, and R. R. Barton, 1601 - 1609. Piscataway, New Jersey: Institute of Electrical and Electronics Engineers, Inc.

Montevechi, J.A.B., F. Leal, A.F. de Pinho, R.F. da S.Costa, F.A.S. Marins, F.F. Marins, and J.T. de Jesus. 2008. Combined use of modeling techniques for the development of the conceptual model in simulation projects, , In Proceedings of the 2008 Winter Simulation Conference, eds. S. J. Mason, R. R. Hill, L. Mönch, O. Rose, T. Jefferson, J. W. Fowler, 987 - 995. Piscataway, New Jersey: Institute of Electrical and Electronics Engineers, Inc.

Nist. 1993. Integration definition for functional modeling. Federal Information Processing Standards Publications, FIPS PUB 183.

Perera, T., and K. Liyanage. 2000. Methodology for rapid identification and collection of input data in the simulation of the manufacturing systems. Simulation Practice and Theory 7 (7) 645-656.

Ryan, J., and C. Heavey 2006. Process modeling for simulation. Computers in Industry 57 (5) 437-450.

Wang, W., and R.J. Brooks. 2007. Empirical investigations of conceptual modeling and the modeling process, In Proceedings of the 2007 Winter Simulation Conference, eds. S. G. Henderson, B. Biller, M.-H Hsieh, J. Shortle, J. D. Tew, and R. R. Barton, 762 - 770. Piscataway, New Jersey: Institute of Electrical and Electronics Engineers, Inc. 


\section{AUTHOR BIOGRAPHIES}

JOSÉ ARNALDO BARRA MONTEVECHI is a Titular Professor of Instituto de Engenharia de Produção e Gestão at Federal University of Itajubá, in Brazil. He holds the degrees of Mechanical Engineer from Federal University of Itajubá and M.Sc. in Mechanical Engineer from Federal University of Santa Catarina, and Doctorate of Engineering from Polytechnic School of University of São Paulo. His research interest includes Operational Research, Simulation and Economic Engineering. His e-mail address is <montevechi@unifei.edu.br>.

FABIANO LEAL is a Professor of Instituto de Engenharia de Produção e Gestão at Federal University of Itajubá, in Brazil. He holds the degrees of Mechanical Engineer from Federal University of Itajubá and M.Sc. in the same university. His Mechanical Engineering doctorate has gotten from State University of São Paulo. His research interest includes Simulation, Operations Management and Work Study. His email address is <fleal@unifei.edu.br>.

ALEXANDRE FERREIRA DE PINHO is a Professor of Instituto de Engenharia de Produção e Gestão at Federal University of Itajubá, in Brazil. He holds the degrees of Mechanical Engineer from Federal University of Itajubá and M.Sc. in the same university. His Mechanical Engineering doctorate has gotten from State University of São Paulo. His research interest includes Operational Research, Information System, Simulation and Operations Management. His e-mail address is <pinho@unifei .edu. br $>$.

RAFAEL FLORENCIO DA SILVA COSTA is an industrial engineer graduated from Federal University of Itajubá, in Brazil. Currently, he is a student of masters in industrial engineering at the same university. His research interest includes Discrete Event Simulation, Operations Research and Economic Engineering <rafael.florencio@yahoo.com.br>.

MONA LIZA MOURA DE OLIVEIRA is a Production Engineer graduated at Federal University of Itajubá, in Brazil. Nowadays she is a student of masters in Production Engineering at the same university. Her research interest includes Simulation and Conceptual Modelling. Her e-mail address is $<$ monaoli@yahoo.com.br>.

ANDRÉ LUÍS FAUSTINO DA SILVA is a Quality Manufacturing Coordinator of Padtec S.A., in Brazil. He holds the degrees of Electronic Engineer from São Francisco University of Itatiba and Specialist of Quality and Productivity from Federal University of Itajubá, in Brazil. He has more than 18 years of experience in telecommunications area. His current research interests include manufacturing process improvement, reliability modeling and life data analysis. His e-mail address is <andreepadtec.com.br>. 